\title{
Major outcomes of an authentic astronomy research experience professional development program: An analysis of 8 years of data from a teacher research program
}

\author{
L. M. Rebull* \\ Caltech-IPAC/IRSA, SSC, and NITARP, 1200 E. California Boulevard, MS 100-22, Pasadena, California 91125 USA \\ D. A. French \\ Wilkes University, 84 West South Street, Wilkes-Barre, Pennsylvania 18766 USA \\ W. Laurence \\ Create-osity, 3187 Julies Drive, Park City, Utah 84098 USA \\ T. Roberts \\ Caltech-IPAC/ICE, 1200 E. California Boulevard, MS 314-6, Pasadena, California 91125 USA \\ M. T. Fitzgerald \\ Edith Cowan Institute for Education Research, 270 Joondalup Dve, Joondalup WA 6027, Australia \\ V. Gorjian \\ NASA/JPL, 4800 Oak Grove Drive, Pasadena, California 91101 USA \\ G. K. Squires \\ Caltech-IPAC/ICE, 1200 E. California Boulevard, MS 314-6, Pasadena, California 91125 USA
}

(Received 15 September 2017; published 5 July 2018)

\begin{abstract}
The NASA/IPAC Teacher Archive Research Program (NITARP) provides a year-long authentic astronomy research project by partnering a research astronomer with small groups of educators. NITARP has worked with a total of 103 educators since 2005. In this paper, surveys are explored that were obtained from 74 different educators, at up to four waypoints during the course of 13 months, from the class of 2010 through the class of 2017; those surveys reveal how educator participants describe the major changes and outcomes in themselves fostered by NITARP. Three-quarters of the educators self-report some or major changes in their understanding of the nature of science. The program provides educators with experience collaborating with astronomers and other educators, and forges a strong link to the astronomical research community; the NITARP community of practice encourages and reinforces these linkages. During the experience, educators get comfortable with learning complex new concepts, with $\sim 40 \%$ noting in their surveys that their approach to learning has changed. Educators are provided opportunities for professional growth; at least $12 \%$ have changed career paths substantially in part due to the program, and $14 \%$ report that the experience was "life changing." At least $60 \%$ express a desire to include richer, more authentic science activities in their classrooms. This work illuminates what benefits the program brings to its participants; the NITARP approach could be mirrored in similar professional development programs in other STEM subjects.
\end{abstract}

DOI: 10.1103/PhysRevPhysEducRes.14.020102

\footnotetext{
*rebull@ipac.caltech.edu
}

Published by the American Physical Society under the terms of the Creative Commons Attribution 4.0 International license. Further distribution of this work must maintain attribution to the author(s) and the published article's title, journal citation, and DOI.

\section{INTRODUCTION}

Science education has been in an on-going state of reform [1]. Previously, the emphasis was on incorporating inquiry-based pedagogies in the classroom [1]. With the adoption of the Next Generation Science Standards (NGSS) [2] by many states, current reform efforts call for $\mathrm{K}-12$ science education to incorporate authentic scientific inquiry, which models the behaviors of practicing 
scientists $[3,4]$. Incorporating authentic scientific inquiry may be a daunting task, as educators may not have had that experience themselves. Approximately two-thirds of physics, physical science, and earth science teachers do not have majors, minors, or certifications in these areas, but are teaching this content (Schools and Staffing Survey 2012 as cited in Marder [5]); Ref. [6] reports that $80 \%-90 \%$ of educators hold certifications in their subject, but that is not the same as having an undergraduate major or minor in their field, or for that matter science research experience. An informal survey of a very small sample of 61 educators [7] suggests that about $40 \%$ of educators did not have undergraduate research experiences at all. Professional development (PD) opportunities for science teachers have been changing to meet the shifting demands in the classroom. Science PD programs have been moving away from the one-day, "sit and get" workshop formats to longer PD formats that take place over several months to one year [8]. Such formats have been shown to be more effective at enacting teacher change [9]. An example of the dozen or so such programs available for educators in any physical or biological science include the Research Experience for Teachers (RET) and Math and Science Partnership (MSP) programs supported by the National Science Foundation (NSF); Fitzgerald et al. [10] include several astronomy programs involving high school educators.

Though the NGSS calls for teachers to incorporate more authentic scientific inquiry in the classroom, the research shows teachers may need additional support developing good, scientific research questions and projects. While teachers who have not conducted scientific research may be able to identify flaws in others' experimental designs, teachers may have difficulties developing their own scientific research project [11]. Professional development providing teachers with opportunities to do authentic scientific research by closely collaborating with a research scientist may provide the additional support teachers need in the NGSS era.

A review of the literature yields promising results for PD opportunities where teachers conduct research with scientists. Such programs have been shown to increase teachers' content knowledge [12-15]. They have also been shown to increase teachers' knowledge and confidence of using scientific and laboratory instruments and techniques $[12,16]$.

Participating in a scientific research experience has led to changes in the classroom. After participating in scientific research, teachers increased lab experiences for their students [16]. Teachers also incorporated more inquirybased pedagogies in their classroom [13,14,16,17].

Collaborating with a scientist was reported to positively change teachers' views of science and scientists [13]. Teachers reported being more enthusiastic about science and science research [16]. Teachers reported continuing the collaboration with their mentor scientist $[15,16]$. Finally, teachers noted their appreciation for opportunities for collaboration and support from scientists $[12,14]$. This suggests that teachers are developing and sustaining a community from participating in research experiences.

The most substantial previous work on teacher research experiences specifically in astronomy is Buxner's qualitative study [18] of teachers' understanding about scientific inquiry and the nature of science within three different summer teacher research experience programs. Project durations in this study ranged from one week to two months. Buxner found that the outcomes intended by project directors, such as strong changes in teachers' understanding of science inquiry and how to implement research with their students, did not commonly occur, although smaller magnitude improvements were noted. However, teachers self-reported significant changes in their science pedagogy, personal and professional growth, confidence, and effective classroom activity. However, Buxner goes on to note that "systematic research across multiple programs using similar protocols is highly limited." Additionally, when researching the Students, Teachers, and Rangers, and Research Scientists (STaRRS) studentteacher-scientist partnership, Houseal et al. [13] found "shifts in teachers' attitudes regarding science and scientists, and shifts in their pedagogical choices" (p. 84). Research into teacher research experiences is also lacking outside of astronomy. Sadler et al. [19] explore 53 studies of science research apprenticeship experiences, of which 11 were focused on teachers. They call for a greater methodological diversity, to explore more ways of direct and valid measures of outcome variables and also, most relevant to this particular study, is to provide fine-grained analyses of programmatic features to yield additional insights.

NITARP, the NASA/IPAC Teacher Archive Research Program [20], has worked with more than 100 teachers over the last 10 years. Small groups of participant educators are paired with a mentor astronomer and involved in a yearlong research project using professional astronomy tools and archival data. The teams present their results at the American Astronomical Society (AAS) meeting in science poster sessions. Participants have primarily been high school teachers [21]. Here, both the words "educator" and "teacher" are used to refer to the program participants.

Other recent papers describe NITARP in more detail [22]; see Rebull et al. [21] for more discussion specifically about the motivations of educators for participating in NITARP, with ramifications for supporting teachers through a research program.

In this paper, we ask the following: How do educator participants describe the major changes and outcomes in themselves fostered by NITARP? This study focuses in particular on the last eight years, specifically the 74 NITARP educator participants from those years. The empirical data are primarily composed of regular surveys of, and reports from, participants. Qualitative explorations of the data provide important knowledge about self-reported teacher 
participants' learning experiences in such projects and how the teachers change as a result of such projects. To emphasize again, this is primarily a summary of self-report evaluation data, though not all of the themes discussed here were specifically targeted with survey questions. Despite the fact that there is a single project discussed here, in terms of Yin's terminology [23], this is a type IV case study where there are multiple cohorts, multiple contexts, with multiple units of analysis.

Because this research examines how participating teachers describe their experiences, a social constructivist theoretical framework was used [24]. Constructivism is an interpretivist theoretical framework; the researchers' goal is to "describe the practice" (Koro-Ljungberg et al. [24], p. 690) within constructivism. To gain insight as to how teachers described changes and outcomes from participating in NITARP, data were collected from teacher participants primarily at four waypoints throughout NITARP, but data are also used from informal and/or smaller-scale surveys of participants and alumni. Of the themes described in this paper, about half of them emerged upon reading all the surveys, and the other half were specifically probed on the feedback forms. The content validity is given by triangulation of multiple data sources (surveys at four waypoints), as well as member checking via participant feedback given to the researchers [25].

In this paper, a very brief overview of NITARP is first provided (Sec. II); see Rebull et al. [21,22] for more information. The data are briefly summarized in Sec. III. Section IV lists the major changes and benefits fostered by NITARP, as self-reported by participants, including a deeper understanding of the nature of science, increased desire and skill in collaboration, connections to the astronomy research community, comfort with the unknown, enhanced student empathy, refinement of their own professional goals, and inclusion of richer, authentic science activities. Section V summarizes the results.

\section{NITARP OVERVIEW}

In order to answer the research question about the impact on educators, at least a simple description of NITARP must be provided.

NITARP's goal is to provide a long-term PD experience, enabling teachers to experience the authentic research process. NITARP sets out to deepen educators' understanding of the nature of scientific research, and ultimately positively impact their current and future students via changes in pedagogy.

In this section, the NITARP project is very briefly described. For a longer description of the program, please see Rebull et al. [21,22]. Because the present paper includes a discussion on the longer-term impacts of NITARP on its participants, this section also highlights the ongoing community of NITARP alumni. Table I includes some basic demographic information.

\section{A. Program context}

The authors of this paper include the NITARP director (L. M. R.) and deputy (V. G.), NITARP alumni (W. L., D. A. F.), education researchers (T.R., W.L., M.T.F., DAF), staff at IPAC involved in formal and informal education (L. M. R., T. R., V. G., G. K. S.), and professional astronomers (L. M. R., V. G., M. T. F., G. K. S.). Because we are so heavily involved in running the program, we can use the insight provided by our experience to tell a more complete picture of the NITARP program and what teachers take away from the program. Additionally, because the researchers include participants, this allowed for the researchers to easily clarify participants' response. This member checking ensured the validity of these data. NITARP is continually changing and adapting to the needs of participants.

Coding was used to analyze the open-ended responses on the surveys given at the four waypoints [26]. Participant responses were obtained, organized, read, coded for initial themes, then read again, coded for emergent themes. The themes were connected to paint a clearer picture regarding participants' views about their NITARP experience.

\section{B. High-level summary}

NITARP partners a small team of 4-5 educators with a mentor astronomer. Most ( 70\%) NITARP participants are high school classroom teachers; there are some middle school classroom educators and fewer still nontraditional educators. One of the educators on each team is a mentor teacher who has been through the program before and acts as a deputy lead of the team. The NITARP year starts with a trip to the winter AAS meeting in January. Right before the AAS meeting is a day-long "NITARP Bootcamp" in which they meet their team and start to explore both their science and the expectations of the program. At the AAS they see how scientific discourse is conducted at meetings. They return home and work remotely as a team to write a proposal; the proposal is reviewed by a panel of educators and astronomers, and the teams must respond to the comments. The teams continue to work remotely through the spring and into the summer. In the summer, the teams travel to the California Institute of Technology with up to four students per teacher for about a week to work intensively with the data. They return home and finish the research through the fall. Finally, they write two posters, one science and one education, that they take back to the AAS (with students) in January. They present their work in science poster sessions along with other astronomers at the meeting. NITARP pays all reasonable travel expenses for the teacher to the first AAS, and the teacher plus up to two students for the summer visit and the second AAS.

\section{Participant selection}

NITARP recruits and selects participants from a nationwide application process. Recruitment is primarily through 


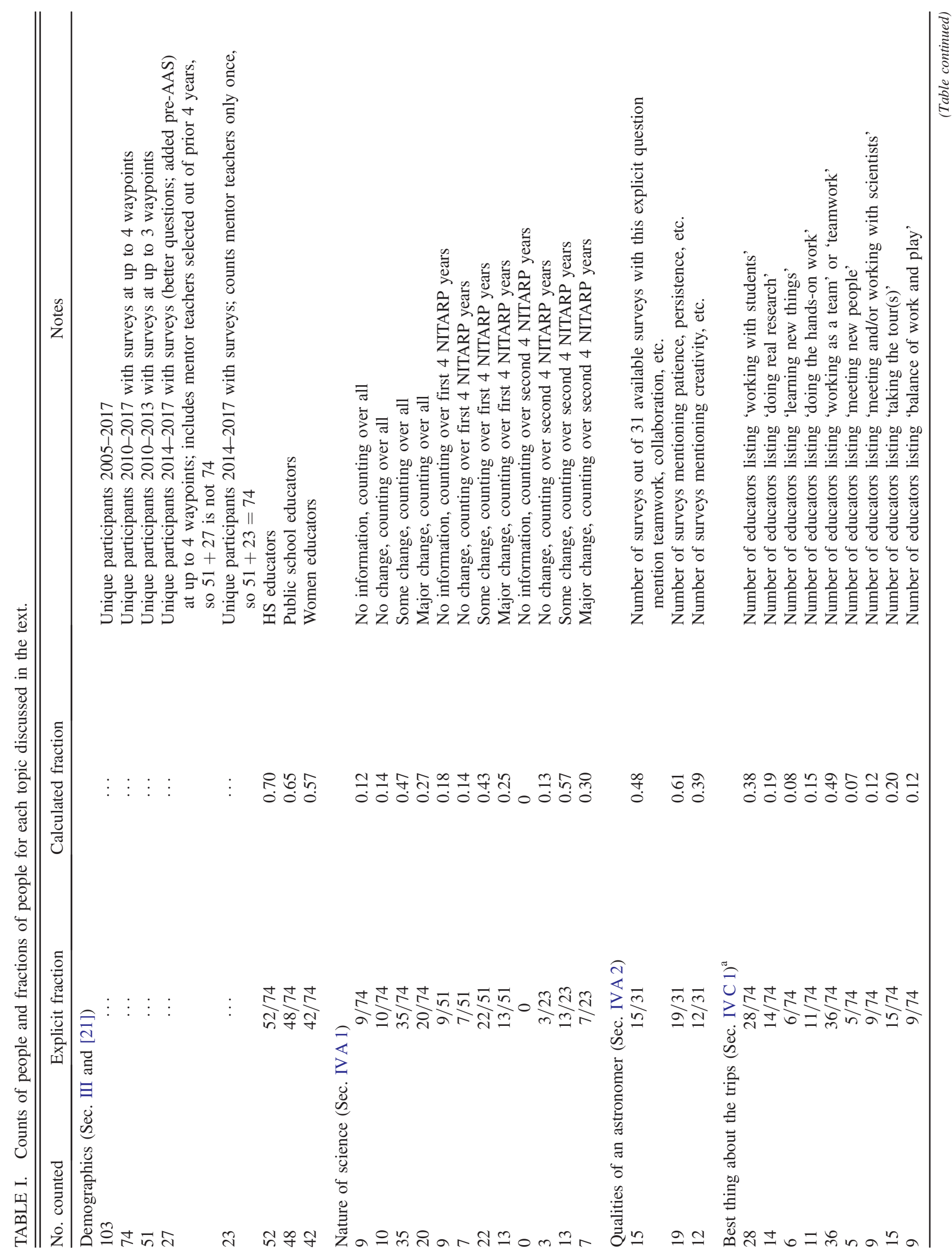




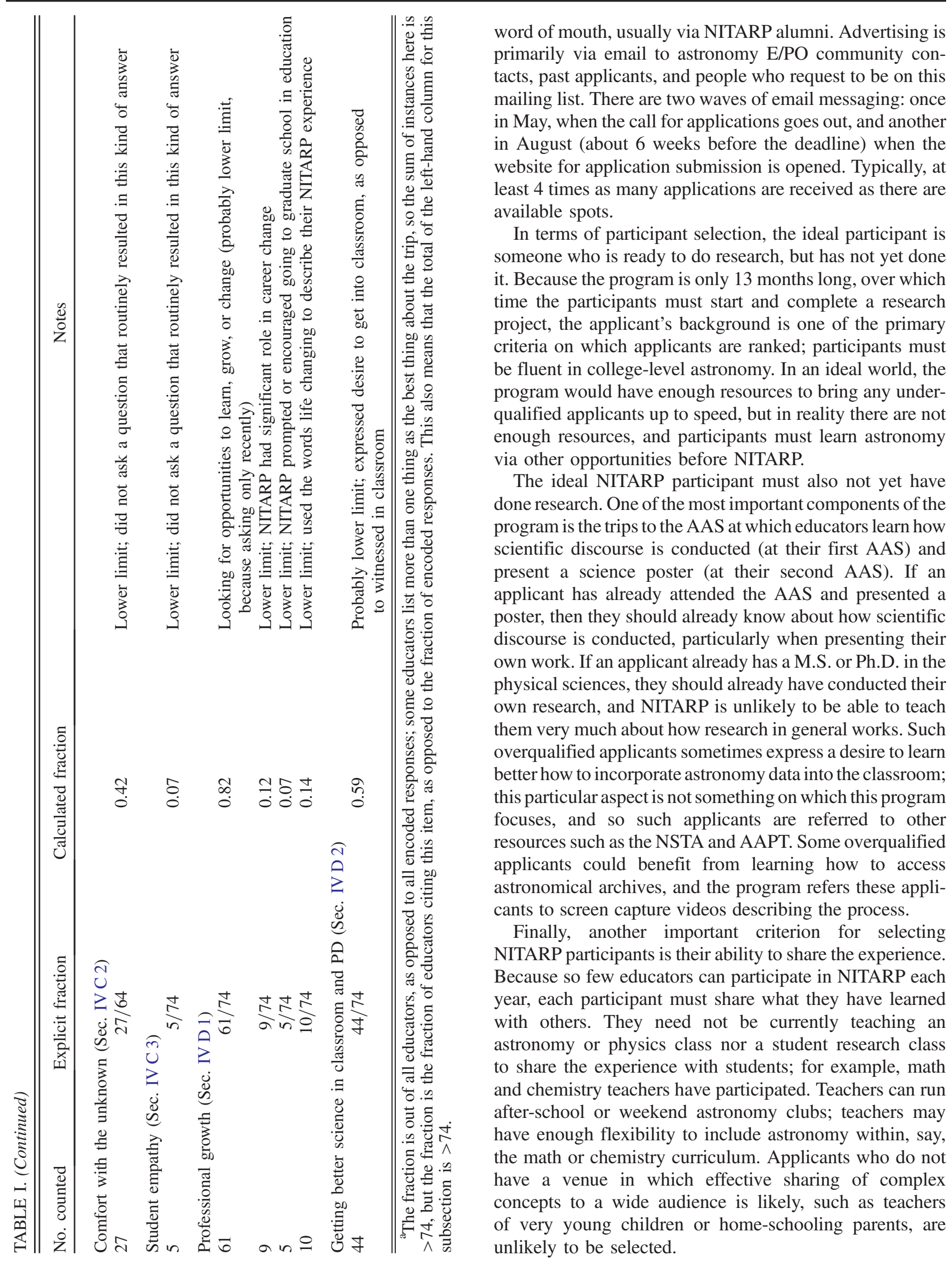




\section{NITARP as effective PD}

As discussed in Rebull et al. [21], NITARP aligns well with the characteristics of effective PD. The National Science Teachers Association (NSTA) Position Statement and Declaration on Professional Development in Science Education [27] includes the sentence, "To best serve all students as they learn science, professional development should engage science educators in transformative learning experiences that confront deeply held beliefs, knowledge, and habits of practice." Recall the research question: How do educator participants describe the major changes and outcomes in themselves fostered by NITARP? As shown here and below, NITARP engages educators in transformative learning experiences.

The NITARP experience was one of the best professional development experiences I have had.-NITARP educator, 2013 class

The NITARP program has opened my eyes to a whole new world-it has had a enormous impact on what I do, how I do it, and what my students are exposed to. I really cannot imagine what I would be doing now if I had not gotten involved with this program-the difference that it has made in my life is truly amazing. -NITARP educator, 2016 class

I've been involved in many professional development activities and this is by far the best one I've ever done.NITARP educator, 2010 class

\section{E. On-going community}

A community of practice (COP) [28] is "a group of people who share a concern, a set of problems, or a passion about a topic, and who deepen their knowledge and expertise in this area by interacting on an ongoing basis" [29]. Continuing to quote from Ref. [29], A COP's "purpose is to create, expand, and exchange knowledge, and to develop individual capabilities" where members self-select "based on expertise or a passion for a topic." Holding them together in the COP is "passion, commitment, and identification with the group and its expertise." COPs "evolve and end organically as long as there is relevance to the topic and value and interest in learning together." A NITARP COP is actively supported through regular contact with and among the alumni. The NITARP COP's purpose is to share knowledge about current events in astronomy (such as press releases or new journal articles, not "what's in the sky this month," which can be found via many other venues), in astronomy education, and other items such as new opportunities to participate in other programs, as well as events within the NITARP year. The program maintains a mailing list where opportunities are shared and where teachers can ask for help. The members are selected to join via selection for NITARP, but they are free to unsubscribe from the mailing list; nearly all of the alumni have maintained their subscription to the mailing list, even through job changes (or retirement), as manifested by changes in email addresses in the list. Thus, the NITARP COP meets the criteria of self-selection based on passion and commitment; the group and its expertise is seen as valuable. Mail traffic on this list is largely from the NITARP management to the community, but at least once every 4-8 weeks, queries from alumni go out asking for help in solving a problem, say, in the classroom or getting students more involved in research, etc. Additional teacherto-teacher direct contact occurs, as manifested by subsequent collaboration and products. There is no restriction on topics in the list, and the topics covered in the list evolve with time, meeting the last quality listed for a COP.

Further, Ref. [30] describe COPs as "Communities of practice are groups of people who share a concern or a passion for something they do and learn how to do it better as they interact regularly." They go on to list three characteristics: (i) "The domain: [...] It has an identity defined by a shared domain of interest. Membership therefore implies a commitment to the domain, and therefore a shared competence that distinguishes members from other people." (ii) "The community: In pursuing their interest in their domain, members engage in joint activities and discussions, help each other, and share information. They build relationships that enable them to learn from each other; they care about their standing with each other." (iii) "The practice: [...] Members of a COP are practitioners. They develop a shared repertoire of resources: experiences, stories, tools, ways of addressing recurring problems-in short a shared practice." NITARP combines all three of the defining characteristics for a COP. Members of the COP clearly share a passion for astronomy teaching, and they learn from each other how to improve their teaching and astronomy research skills by interacting regularly. They have a shared competence that distinguishes them from other educators; many NITARP educators win awards (see the incomplete list on the NITARP website). They engage in joint activities and help each other, sharing information. They share experiences, tools, and approaches for doing research with students. More focused subgroups appear within the community, such as those in elite private schools or those in remote rural public schools, to address those groups' specific needs. NITARP meets the qualities listed for a COP.

In recent years, a "continuing education" video series has been initiated for the NITARP COP, sharing new tools and data releases. These videos are posted publicly via YouTube. Many videos have taken on a life of their own; the videos on ds9 (a tool for viewing FITS [31] images) were posted - by the ds9 staf-on Harvard's main ds9 page. Additionally, through affiliation with NASA-JPL, the alumni community also has access to telecons aimed at a broader audience and covering current events in space exploration and astronomy.

As discussed later in Sec. IV B 2, many of the alumni continue to do research or similar activities, either with 
their original team or with a new team composed of other alumni. This ongoing involvement in research activities also contributes to the COP.

Not only can I analyze astronomical data to find scientifically useful results, but I can publish my work as a poster and be part of this community. I did not feel like a stranger or usurper or even out of place-it felt like I belonged.-NITARP educator, 2014 class

The reality of taking the children to the AAS was more than I could have imagined. The excitement on their faces as they saw the community that they were now a part of and the fact that they were able to experience the independence of presenting the work to professionals, and feel successful doing so. I watched students who came in apprehensive and nervous and they blossomed as they got comfortable and practice. It was beautiful to see.-NITARP educator, 2016 class

I think that future support will be needed if I am able to try independent work-but that might be from the great network of alumni and astronomy community as well.NITARP educator, 2017 class

I am very grateful to be again part of such an amazing and dynamic group of people and always love how supportive and encouraging the NITARP community is.-NITARP mentor educator, 2017 class

\section{DATA}

The data that are the primary focus of this analysis are discussed in detail in Rebull et al. [21]; here we briefly summarize the data. Important numbers are summarized in Table I. Themes discussed in the rest of the paper are summarized in Table II.

Since 2005, 103 teachers have participated in NITARP (or its immediate predecessor). We use detailed, written survey data from 74 teachers collected over the most recent 8 years, 2010-2017. At up to four waypoints during each NITARP year, surveys were collected from participants:
- Pre-AAS: Before their first AAS (initiated with the 2015 class);

- Post-first-AAS: After the NITARP Bootcamp and their first AAS;

- Summer: After the summer work session (includes teachers and students who participate in this visit);

- Post-second-AAS: After their second AAS at which they presented their results (includes teachers and students).

Nearly twice as many educators were involved in 2010 2013 as compared to 2014-2017 [21]; see summary in Table I. The surveys were substantially changed in the middle of 2014 as a result of "boots-on-the-ground" experiences in the first four years, coupled with a better understanding of the education research literature (see Rebull et al. [21] for a complete list of survey questions). Despite 95\%-100\% participation from teachers on the surveys in general, data from the first four years (20102013, but particularly 2010) are less complete than data from the most recent four years (2014-2017). Therefore, by number, there are more people in the earlier years, but more and better surveys (and answers) in the later years. Of the 74 educators, $70 \%$ are (or were at the time) high school educators, $65 \%$ are or were public school educators, and $57 \%$ are women [21].

While the educators originate from a wide variety of states and types of schools or programs, it is frequently the case that the participants are already quite accomplished educators, and they tend to seek out opportunities to learn and improve their practice. In the context of the present work, which is heavily based on self-reported changes, it is important to note that these teachers are highly capable of recognizing changes in their teaching approach and/or philosophy. These individuals' ability to reflect upon their growth, critically analyze themselves, and answer with great richness and detail, lends validity and weight to their self-reported changes.

All answers to the collected surveys were examined, and emergent themes were sought. Themes of broad interest

TABLE II. List of themes, section in which the theme is discussed, number of quotes included, and whether or not the theme was emergent.

\begin{tabular}{lcccc}
\hline \hline Theme & Section & No. quotes & \\
a & a priori or emergent & Notes \\
(NITARP as effective PD) & II D & 3 & $\ldots$ & (from NITARP summary) \\
(NITARP and ongoing community) & II E & 4 & $\ldots$ & (from NITARP summary) \\
Nature of science & IV A 1 & 12 & a priori & \\
Qualities of an astronomer & IV A 2 & 13 & a priori & Emergent first 4 yrs; a priori second 4 yrs \\
Collaboration and sharing & IV B 1 & 8 & Emergent & \\
Links to astronomy research community & IV B 2 & 4 & Emergent & \\
Best thing about the trips & IV C 1 & 6 & a priori & \\
Comfort with the unknown & IV C 2 & 12 & Emergent & \\
Student empathy & IV C 3 & 2 & Emergent & \\
Professional growth & IV D 1 & 4 & a priori & Emergent first 4 yrs; a priori second 4 yrs \\
Better science in their classrooms and PD & IV D 2 & 8 & a priori & Emergent first 4 yrs; a priori second 4 yrs \\
\hline \hline
\end{tabular}

\footnotetext{
${ }^{\mathrm{a}}$ Number of quotes included in this paper, not number of total quotes available.
} 
("What is 'real astronomy'?") were probed with explicit questions (survey questions appear in their entirety in Rebull et al. [21]). In the context of this work, new themes emerged upon reading the responses in aggregate, as described below. The surveys were then re-read to look for those emergent themes. In some cases, the answers were iteratively coded for emergent themes; also see Rebull et al. [21]. Themes are listed in Table II with an indication as to whether they were identified a priori or emerged as part of this work.

Quotes used in this paper primarily come from these surveys. Some quotes are extracted from email from teachers to management or to mentor scientists. There was also a brief survey that attempted to quantify NITARP impact from 2005 to 2013; results from that appear in Rebull et al. [32], available on the NITARP website. Some quotes from that survey appear in this paper. Finally, a few quotes come from informal surveys that some teams did as part of their education AAS posters. All of these education posters are available on the NITARP website. The fact that similar themes can be identified in quotes originating in very different surveys lends support to these results.

\section{FINDINGS: MAJOR CHANGES AND BENEFITS FOSTERED BY NITARP}

This paper has a primary goal of probing how educator participants describe the major changes and outcomes in themselves fostered by NITARP.

In looking at the survey results and thinking about the higher-level and longer-term gains seen in the educator participants, there are some noticeable trends. The skills that are fostered in these educators, or skills that the program hopes to foster, are also to some extent characteristics of successful professional astronomers. In the application process, teachers who are ready to learn these skills, or have already started to learn these skills, are actively sought. There is evidence from the feedback forms that they learn these skills over the year, but there is also evidence of continued development of these skills among the alumni community, via emails to the NITARP mailing list, and continued communication with the scientists.

This section discusses major changes and benefits fostered by NITARP grouped under four major categories: perceptions of science and scientists; impact of collaborations; views of learners; pedagogical changes and professional growth.

\section{A. Perceptions of science and scientists}

\section{Nature of science}

Understanding the nature of science is often cited as a primary goal of many different educational programs aimed at teachers and/or students. The nature of science can be interpreted in many ways $[33,34]$, but here we adopt the meaning as in Lederman [34], where "nature of science" means how science accumulates evidence and science as a way of learning about the world.

Because the educators have to start and finish a research project in a year, participants are selected to already be fluent in college-level astronomy. Therefore, many of them already are confident before starting the program that they know about astronomers ("astronomers are real people"; see Sec. IVA 2 for more on this) and astronomy (and how science works in general). Since one of the major program goals was to change how teachers think about science and scientists, questions probing this were included on the feedback forms starting early in the program. Survey questions appear in their entirety in Rebull et al. [21], but the ones most relevant to this discussion are, "Did this experience change the way you thought about astronomy or astronomers?" and to a lesser extent, "Did you do anything on this visit that you expected would be part of scientific research? Or anything that you did not think would be part of scientific research?"

Based on the open-ended responses in their surveys, the educators can be placed into one of four bins:

(1) "No information": Those educators for whom there is no information, where literally this question was not asked or no answer to that question was provided.

(2) "No change": Those educators reporting no change in understanding. For example, in response to "Did this experience change the way you thought about astronomy or astronomers?" an educator might respond, simply, "No." (Also see quotes below.)

(3) "Some change": Those educators reporting some change in understanding, or a more nuanced understanding. For example, in response to "Did this experience change the way you thought about astronomy or astronomers?" an educator might respond, simply, "Not really, but I had no idea that there were so much public data available," or "Not really, but I didn't know how much computer programming was involved." (Also see quotes below.)

(4) "Major change": Those educators reporting a major change in understanding. For example, in response to "Did this experience change the way you thought about astronomy or astronomers?" an educator might respond, "Yes, it has revolutionized my understanding!" (Also see quotes below.)

Overall, for $12 \%$ of the educators, there is no information about this topic, either because they were not asked, or they did not answer the question; all of these educators are from the first four years. About $14 \%( \pm 5 \%$, assuming Poisson statistics) of educators report that this program did not change their opinion of science or scientists or astronomy or astronomers; they already felt that they knew what real science or scientists were like, and their experience did not change that. Just under half $(47 \% \pm 10 \%)$ report that there was some change in their 
opinion; for example, they report an increased appreciation for how much data are in astronomical archives, or that there was a lot more programming than they expected, etc. Finally, $27 \%( \pm 7 \%)$ report major changes in their understanding, a revolution in their thinking. Figure 1 visualizes the fractions of the samples in each bin. Because the wording of our questions changed somewhat, plotted here are the aggregate counts (solid line), but also the first period of four years ("NITARP-first 4", dotted line), as distinct from the second period of four years ("NITARP-second 4", dashed line).

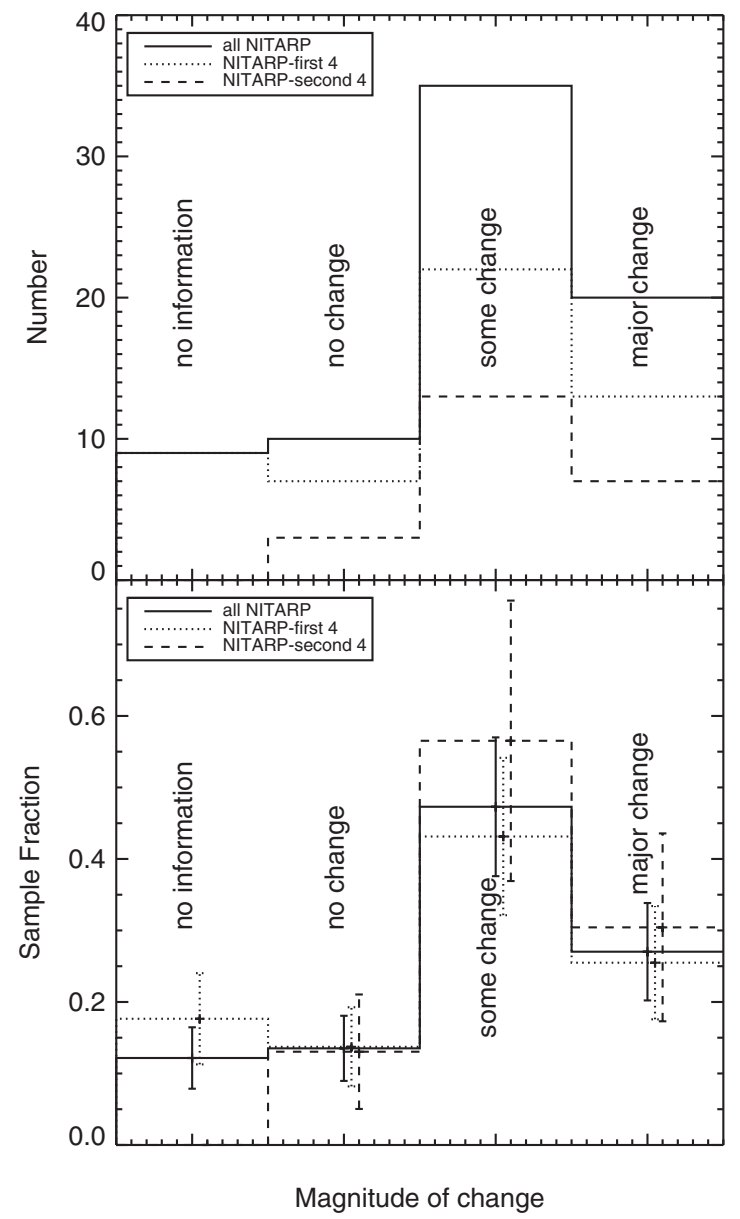

FIG. 1. Numbers (top) and fractions (bottom) of educators who report changes in their understanding of the nature of science. The first bin is those educators for whom there is no information, the second bin is those reporting no change in understanding, the third bin is those reporting some change in understanding (a more nuanced understanding), and those who report a major change in understanding. Because the wording of our questions changed, plotted here are the aggregate counts (solid line), but also the first four years of NITARP ("NITARP-first 4", dotted line), as distinct from the second four years of NITARP ("NITARP-second 4", dashed line). Errors shown in the second panel assume Poisson statistics, and are slightly offset for clarity. About $74 \%( \pm 13 \%)$ of educators report either some or a major change in their understanding of the nature of science.
This experience has completely changed my once shallow view of astronomy and astronomers. -NITARP educator, 2015 class (major change)

Before ever having experienced an American Astronomical Society meeting I thought I was well versed in the astronomer's culture. [...] My experience has been one of culture shock. Astronomers, all of whom are scientists, can be personal, funny, and outright social beings. The nature of their work-retracing their steps for accuracy, being critical of fellow colleagues, and looking to develop the next best project that has not been accomplished already-requires astronomers to discuss, inquire, and exchange their ideas with one another.NITARP educator, 2013 class (major change)

One evening, while working on some homework, I had the realization that THIS WAS REAL. There is no right answer, in fact, no one knows the answer. I can't just go and ask someone the answer. It was like a light bulb went off and I experienced a feeling of excitement and also felt a little bit scared. I thought to myself, "Is this how astronomers feel about their work?" It was a great feeling and exciting that I too am part of this now.NITARP educator, 2012 class (major change)

The entire experience was "real astronomy." Nothing was canned. None of us in the room knew what the "final answer" was. Students really buy into the fact that this is real research. We may only find five new young stars, but when we do, we will be the only people on the planet that know that they are there. How cool is that? They get to go through the process of science and learn, as Feynman would put it,"the kick in the discovery!"-NITARP educator, 2012 class (major change)

When my past students did astronomy research projects, they used data that they themselves collected[...] After working at Caltech with the group, though, I have come to realize that what my students have been doing previously were small projects compared to our [NITARP] studythey were really just glorified lab activities [because I knew what they were going to find before they started]. I have been giving a lot of thought to this since I returned home and am planning major changes in the sort of projects that my research students will be working on in the future.-NITARP educator, 2013 class (major change) Well, here's the thing: as an engineer familiar with rigorous mathematical modeling and iterative problem solving, I thought I could do science; I thought it was basically the same thing, only with theories instead of problems. Thinking I "had what it takes to be a scientist" turns out to have been hubris. In other words, I would have answered this question with [I know what science is] and I would have been wrong.-NITARP educator, 2016 class (major change)

The process of gathering and analyzing data was very important to help show my kids what real research is like. And since our data didn't come out nice and neat 
like some labs do, it really helped push my kids to think outside the box.-NITARP educator, 2013 class (some change; note this person is focused on student learning in this quote)

I never realized how much computer programming is done in Astronomy. I think this will help me reach out to students who might not be interested in 'science.' These students may not realize that their programming skills are vital for analyzing astronomical data.-NITARP educator, 2011 class (some change)

It has changed a little -I now realize that the data does not have to actually be collected by the scientist, but can be collected by anyone. In fact, much science is now done by "data mining" where the data may have already been collected, often for some other purpose, but can be mined for things that the original project did not conceive of.-NITARP educator, 2016 class (some change)

I have always loved astronomy and have had great interactions with many great people in the field so my thoughts on [astronomers] are just as positive as ever.NITARP educator, 2017 class (no change)

No [it did not change my thoughts on astronomy or astronomers]. I'm just really impressed with how much everybody loves what they do.-NITARP educator, 2011 class (no change)

I have been around astronomers and astronomy enough to only have my current views reinforced, which are that as a discipline, astronomy has some of the kindest and most passionate scientists around. They are great fun to work with.-NITARP educator, 2016 class (no change)

In summary, three-quarters $(74 \% \pm 13 \%$, assuming Poisson statistics) of the educators report either major or some change in their understanding of the nature of science as a result of their experience. There is some indication that the changes in the participating students' understanding of the nature of science may be substantially more profound, and we leave further discussion of this to a future paper. Similarly, changing teachers' understanding of science is most likely distinct from making sure that this understanding is conveyed to subsequent students in the classroom (those who did not come on the NITARP trips) or other educators; this is also beyond the scope of the present work. Buxner [18] found that strong changes in teachers' understanding of science inquiry did not commonly occur in three different summer teacher research programs, so it is important, but beyond the scope of the present work, to follow up on the longer-term ramifications of the NITARP educators' self-reported changes in understanding, specifically as it applies to the classroom.

\section{Qualities of an astronomer}

As discussed in Sec. II C, the participants are selected to have a college-level understanding of astronomy, and come into the program often confident that they know all about astronomy and astronomers. However, in many cases, NITARP up ends that understanding. At the beginning of NITARP (and in the preceding years), it had been assumed that the educators already knew that "astronomers are real people," and that astronomers (at least for the most part) do not look like the popular scientist stereotype of an older white man with a lab coat and bad hair (e.g., Refs. $[35,36])$. However, in the first four years of feedback forms, it became apparent that some educators did not know this, and so in the most recent four years of data, the surveys explicitly asked, "What qualities do you think are important to be an astronomer?" After careful review of participants responses, additional themes emerged. For example, see the second quote in Sec. IVA 1; it says, "Astronomers, all of whom are scientists, can be personal, funny, and outright social beings." In answers to the questions about things participants thought were surprising, or things that they noted particularly after their first AAS trip, it can be seen that many participants had misconceptions about what astronomers look like or how they interact. NITARP has dispelled these misconceptions.

The route into astronomy is more varied than I thought. More people have access than I anticipated. I would never have thought someone who was older, coming from community college would end up with a Ph.D. in astronomy, working at Caltech. Or that a girl who thought she couldn't do math well into college would end up in astronomy. These stories were encouraging.NITARP educator, 2012 class

I am used to seeing older people as astronomers as we watch NOVA and other videos or read about past astronomers in class.-NITARP educator, 2012 class Astronomers are a remarkably collaborative lot. I knew this, but I was amazed by how friendly everyone was. For the most part I was clear that I was a teacher, and they probably had nothing to gain by talking to me. For most people, this was not a deterrent.-NITARP educator, 2012 class

I learned that astronomers are much more down to earth than I envisioned a lot of them to be and so many of them are very willing to go out of their way to explain things when we have questions.-NITARP educator, 2011 class

This experience certainly has changed my thoughts about astronomy and astronomers. I really did not know what they did except teach college classes. I enjoyed seeing the less formal and family friendly atmosphere at [Caltech]. This experience will be shared with my students for some time.-NITARP educator, 2015 class

More broadly, Fig. 2 is a word cloud of the words used in responses from 2014 to 2017 to this question "What qualities do you think are important to be an astronomer?" 


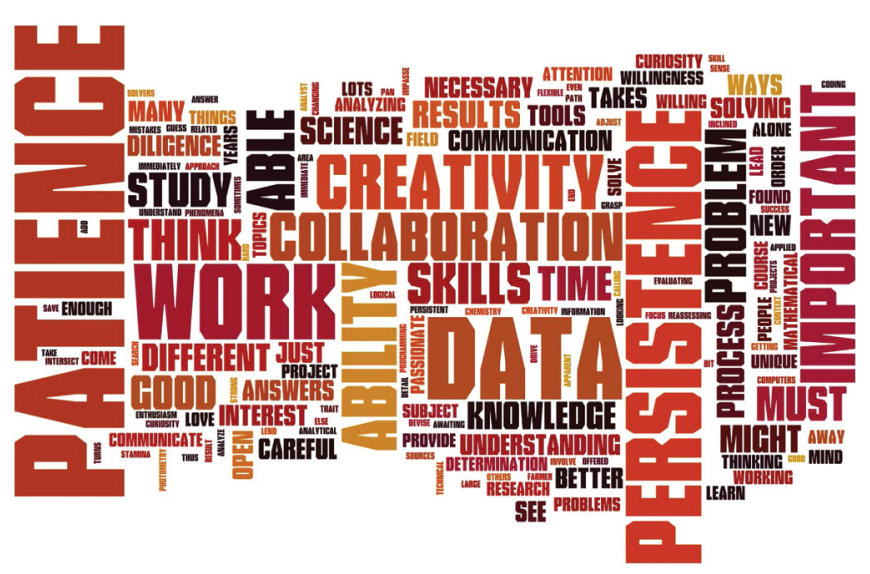

FIG. 2. Qualities of an astronomer. Words that have prominence in this word cloud include patience, persistence, creativity, and collaboration.

Some of the words that appear there prominently are ones that people might likely use to describe scientists of any sort-work, data, important, problem, study, think, ability or able, skills, and time. A Google search reveals that these kinds of words come up frequently when referring to scientists. However, words that might not come to mind for the average person (or appear more rarely in a Google search) but that have prominence in this word cloud include patience, persistence, creativity, and collaboration.

Specifically in the context of Sec. IV B 1 on collaboration, since collaboration and sharing is often new to these educators, it can be seen that over the years for which there are complete surveys, $30 \%$ of the educators that filled out a survey explicitly asking about the qualities of an astronomer list collaboration as important.

Astronomers need to be independently motivated (be able to work alone with a strong drive) and to also work well in teams (and not just with other scientists). They are problem solvers and love a good mystery. Also, they need to have the patience to stick with a project for years. And they should be able to juggle more than one project at once.-NITARP educator, 2016 class

Real astronomy involves being able to problem solve and think critically, apply process skills, and communicate effectively. There has to be passion about the subject matter as well as a dedication and certain element of dedication to the field. Collaboration is huge...being able to work well with other people. Lots of computer time! -NITARP educator, 2010 class

Based on my experience so far in this program, I have found that real astronomy involves a lot of data processing. In addition, I have found that collaboration is a very important aspect of the process. -NITARP educator, 2013 class

Similarly, out of that same set of feedback forms with the explicit question, $61 \%$ of the educators mentioned patience, persistence, or other similar qualities as important qualities of an astronomer. Finally, 39\% mention creativity.

There are lots of qualities that are important to an astronomer, but two that come to mind are persistence and diligence. Sometimes, the apparent path to solving a problem turns out to lead somewhere else (or not lead anywhere at all). The astronomer has to be aware of this and know when to change course and try another approach-sometimes, this has to be done over and over again before the research problem starts to show results.-NITARP educator, 2016 team

Real astronomy is done in data analysis. This is not what the public sees or imagines. I think that this is one of the great values of the program, particularly for students, but for teachers as well. Participating in research projects is always eye-opening and exciting, but it involves a great deal of hard work and creativity. This last aspect, creativity, is an area where scientists typically receive little credit, but it is where they truly excel. Science, including astronomy, seems like a stodgy and noncreative endeavor on the outside, particularly with the focus on STEM as separate from the arts, which are considered creative.-NITARP educator, 2016 class I think more teachers and people in general should be exposed to the process [of research] more so they can understand how dynamic it can be, how much creativity and tenacity is needed, and how NOT like traditional text books it is.-NITARP educator, 2017 class

Astronomy research often involves using public astronomy archives, and sometimes it only involves using archives. Success in astronomy is not just a result of brilliance (though brilliance doesn't hurt). Success also requires quite a bit of persistence.-NITARP educator, 2015 class

Astronomers need to be curious and persistent. Persistence might involve anything from seeking funding sources to awaiting new technologies that could provide the data you need.-NITARP educator, 2015 class

Specifically because the teachers largely come into NITARP believing themselves already knowledgeable about the nature of astronomer and astronomers, there has been an expectation that the impact on the participating students' understanding of astronomers was more substantial. Schneider [37] explored the impact of students' understanding after their teachers went through an RET program, and found substantial changes in students, though no impact on the teachers, perhaps due to sample size. It is likely that those RET teachers similarly believed themselves already knowledgeable, and there may not have been enough educators to find the ones that had their perceptions overturned. Indeed, as in the Sec. IVA 1 above on the nature of astronomy, there is some indication that the changes in the participating students' understanding of what astronomers look like (and do) may be substantially 
more profound. In one case, a teacher, having read his student's surveys before turning them into NITARP, noted that evidently he had done a poor job in conveying to his students what astronomers look like, because he knew and they did not. We leave further discussion of the impact on students to a future paper.

\section{B. Impact of collaborations}

\section{Collaboration and sharing itself}

For many astronomers, collaboration with colleagues is an integral part of being a scientist. Few astronomers publish single-author papers anymore; most papers are written by collaborations of people [38]. Indeed, studies suggest that the more diverse a research team is, the more significant the results (or at least the more citations the paper gets); see Abt [39] for a discussion of this within astronomy, or Freeman and Huang [40] for a more general assessment.

In contrast, many science teachers work in isolation, though research has shown that collaboration is important (e.g., Refs. [28,41,42]). NITARP is, by its very nature, collaborative; the teachers work in teams. Even if they approach the project initially thinking that they will work on their own within the team, most teachers find rather rapidly that the teamwork itself is a powerful motivator [21]. More specifically, these teams require distance collaboration, which is even more rare among teachers. Participants learn how to take advantage of distance collaboration tools to expand their own network, within and beyond the program.

The importance of working in a team in NITARP, as well as the importance of collaborating and sharing process, progress, and results, was not at all understood prior to this analysis. It emerged, powerfully and obviously, upon reading all the survey answers.

Real astronomy involves working as a team to find an answer.-NITARP educator, 2011 class

I love the connections and sharing that happen between teachers, students, and mentors. This is the part that I believe makes a successful PD or E/PO project very successful-the interactions and networks that are formed between participants at all levels. It builds a working comfort level and common ground that helps drive and support further collaboration and communication.-NITARP educator, 2017 class

NITARP brings science directly into the hands of teachers and students, and demonstrates how science is an active, collaborative, and evolving effort.NITARP educator, 2014 class

My students saw a community of people who truly love what they do and are willing to explain it. They made many contacts and saw what science is all aboutsharing discoveries and collaboration. Most importantly, they discovered that they can do this themselves, that they can belong to this community as well.NITARP educator, 2011 class

Particularly early on, it was not anticipated that the team itself (and the COP composed of alumni) provides a very useful support network, not just for NITARP activities, but other activities relating to education. Some teachers are surprised at how quickly they "bond" with their team, and many continue to collaborate (sympathize, bolster, share resources, etc.) after their research experience year; some educators forge friendships or collaborations with alumni from their own class as well as other classes.

[Another teacher] and I actually shared curriculum for astronomy and bounced ideas off one another. The collaborating is priceless. - NITARP educator, 2014 class The best thing about the trip was the chance to interact with others who are trying to do the same things that I am trying to do. No one else around me tries to do student research (even though I have tried to get other teachers involved), not in my district nor in any of the surrounding ones. It was great to spend time with other teachers (and their students) who are trying to accomplish the same things that I am trying to do.-NITARP educator, 2013 class

I really enjoyed working with the [other] teachers. It was important to help each other out and realize that you are going to make mistakes and hopefully one of the other teachers can bring you up to speed on the different areas.-NITARP educator, 2011 class

Even those teachers who were on teams that "broke" (for whatever reasons) seem to still benefit from the network and support structure provided. The COP is strong enough to maintain the support network even when the team (nominally an educator's closest collaborators) struggles.

Personally, all the professional contacts (at AAS meetings and other teacher NITARP participants) plus access to other programs via these contacts and your email blasts have been phenomenal and expanded what I have been able to accomplish. Through these contacts and programs, I have been able to bring other astronomy related programs to students here at the high school and I have gained new knowledge, too. Our students, over the past few years since I participated in NITARP, have directly benefited from my being accepted into the program. You are a great asset and I appreciate all that you do!-NITARP educator, on a 2013 team with challenges, from an email in 2016

NITARP participants have volunteered the insight that sharing and/or collaboration among the high school science teachers in their school or district is far from widespread, and that NITARP really demonstrates in concrete fashion the power of collaboration. 


\section{Links to astronomy research Ccommunity}

Alumni seek the intellectual stimulation of the NITARP and wider astronomy communities. Many alumni come back to the AAS, raising their own money to attend. There have not been careful records about how many self-funded alumni return; it was first noticed that there was a significant increase in the number of alumni at the 2014 AAS meeting. At the 2015, 2016, and 2017 January meetings, for which there are at least partial records, the number of self-funded alumni educators was comparable to each class size; that is, there are 8-9 teachers per class, and about that many alumni, at least, who have paid their own way back to the AAS. So, out of the NITARP-affiliated educators at the meeting, about a third are alumni. (Because teachers in the class that is finishing up bring many students, and because alumni teachers often bring even more students than they did in their research experience year, there are always more NITARP-affiliated students than educators.) Some alumni come only to AAS meetings near them (for financial reasons); others come to every winter AAS meeting because they have ongoing support from their school and/or community (or in a few cases, from their new job; see Sec. IV D 1).

Some teams continue their work with their mentor scientist after their nominal research experience year. Some alumni create new research teams out of the alumni pool, or they just work with the ever-changing groups of students at their schools. There is always more demand for alumni projects than there is mentor scientist time available. This is not an easy problem to solve.

While survey answers and alumni attendance indicated vaguely the importance of links to the astronomy research community, reflection on the importance of this (and keeping track of numbers of alumni attending meetings) is a more recent development.

One manifestation of these links to the wider astronomy community is that teachers very commonly state that they want more similar experiences, either in astronomy or in other fields. Many write impassioned pleas for NITARP to provide more opportunities for them personally, or to expand and reach more people in more fields.

There is a part of me that really wants to explore ways to make the NITARP model more widely available without watering it down. I wish I'd been aware of this opportunity years ago. [...] NITARP was unique in its format and the focused way in which it works. This needs to be expanded.-NITARP educator, 2016 class I now seek out other teachers and opportunities outside of my own school (as well as within). I am looking for collaborative research experiences so I can share the experience I have had with NITARP. While the experience will not be the same I believe it will be enough to entice other teachers to up their game as well. I have several projects in the works and each have plans of culminating with the students presenting in a professional forum.-NITARP educator, 2015 class

I do a lot of summer PD, and this was by far the best. The ongoing social/professional contact with the scientists, the new social/professional/collegial relationship with students and the expanded professional community with the other teachers are inspiring and unparalleled.-NITARP educator, 2016 class

Many alumni are still involved with the community online. As part of encouraging the COP (Sec. IIE), the mailing list is kept active. It is clear that this is valuable to alumni because they actively seek to remain on the mailing list through job changes.

Let this be your monthly installment of "I really appreciate your emails". I don't know how you developed the capacity to keep up on the events in our field but I rely on you now more than ever.-NITARP educator, 2010 class, from an email sent in 2015

Beyond the mailing list, the alumni community continues to be a link to the research community. Staff remain available to answer any astronomy questions, relay additional opportunities and resources, provide continuing education video tutorials (see Sec. IIE) and pass along research papers with significant results. All of these efforts encourage connections to the research community, as well as a culture of sharing.

\section{Views of learners}

\section{The "Best Thing about the Trips"}

NITARP pays for reasonable travel expenses for three different trips during a NITARP year (see Sec. II B for a description). Especially for the summer visit, the teams are kept very, very busy for 8-9 hours per day, which (given the existent feedback) may be the hardest or longest some students have ever worked. Many teams add to their summer experience by sightseeing in the evening (e.g., Griffith Observatory; Mount Wilson) or on the way out of Los Angeles to their respective homes (e.g., the Stratospheric Observatory for Infrared Astronomy, SOFIA, in Palmdale, $\mathrm{CA}$; college tours). For the AAS, usually there is less ancillary sightseeing because there is no formal NITARPorganized tour, and teachers (and students) have to return to school, which is typically already in session.

Despite the work load, especially since the second two trips include students, the possibility exists that the trips could be regarded as primarily sightseeing field trips, as opposed to the work trips they are. In the pre-NITARP (Spitzer) years, some students were seriously dismayed to learn that they would not be going to Disneyland or the beach. So, even for the first four NITARP years, the feedback forms explicitly asked, "What was the best part of the trip?" This is an open-ended question; it is not 


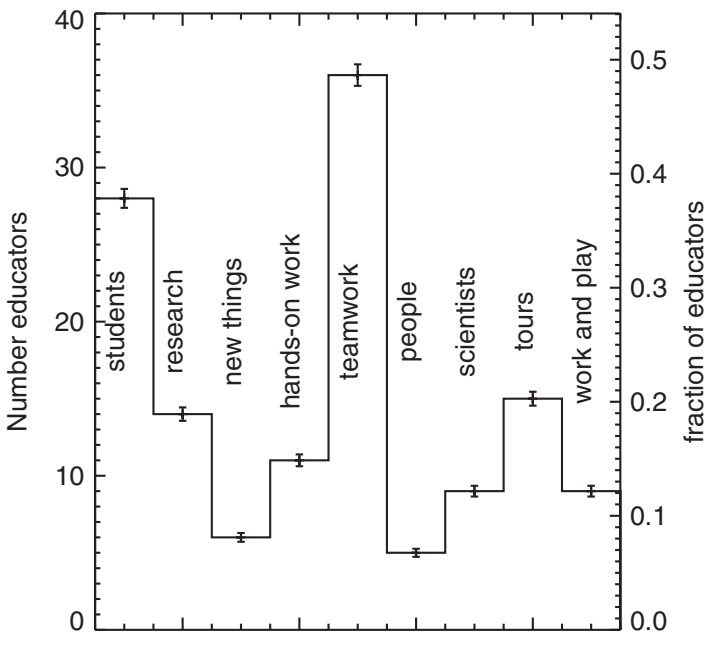

FIG. 3. Number (left axis) and fraction (right axis) of educators' responses to the question, "What was the best part of the trip?" The specific values are listed in Table I. Nearly half the teachers cite teamwork as the best thing about the trips; see the text for additional discussion.

multiple choice. The hope would be that participants would not prioritize the sightseeing over the science.

The responses to the best part of the trip can largely be encoded among 9 categories (see Fig. 3): working with students, doing real research, learning new things, doing the hands-on work, working as a team, meeting new people, meeting or working with scientists, taking the tour(s), and balancing work and play. Some educators mention more than one item, placing them in more than one category. The fractions for the numbers given here, in Fig. 3, and Table I are the fractions of educators (not fraction of responses) whose responses place them into that category.

Basically half the teachers cite teamwork as the best thing about the trips (36 people; 49\%). This was not expected; the importance of the role of teamwork has been underestimated by the NITARP organizers (see Sec. IV B 1 on collaboration and sharing and Rebull et al. [21] for more about the role of collaboration in NITARP). The rate at which teamwork is listed as the best thing about the trip often reflects that the team has, in fact, bonded and learned a lot during the trip.

Getting to be part of a team of astronomers doing science has always been a dream of mine.-NITARP educator, 2017 class

[The best thing was] Getting the opportunity to work on a project such as this with other educators from various disciplines and backgrounds come together to form friendships, working relationships, and build support for the project and each other.-NITARP educator, 2017 class

Students and teachers from all schools worked exceptionally well together.-NITARP educator, 2017 class
Next most popular is working with students, either their own or from other educators $(28 ; 38 \%)$, which perhaps is not surprising for a group of highly motivated teachers (see also Rebull et al. [21]).

My students felt more confident and better understood the big picture much more after the trip. Nothing I could have provided would have allowed for this much growth in these two areas.-NITARP educator, 2014 class

The most interesting part of my experience was how well our student teams bonded to successfully work, and play, together. It was amazing and an important display of cooperative learning. They did not hesitate to help each other as well as the teachers.-NITARP educator, 2015 class

It was very surprising how quickly the students picked up the project and made great strides. They asked questions of [our mentor] and the teachers, which helped clarify information for everyone.-NITARP educator, 2017 class

The remaining structure in Fig. 3 is somewhat more difficult to interpret. Doing real research, learning new things, and doing the hands-on work are all specific goals the program has for the summer visit; 26 unique educators list one or more of these categories (some are coded with more than one of these terms), $35 \%$ of the sample. Meeting and working with new people and/or scientists is less commonly cited, with 14 educators (19\%) mentioning those topics. Finally, 23 educators (31\%) cite the tour(s) or the balance of work and play activities as the best thing about the trip. That means that the goals the program has for the trip (doing real research and learning new things, via hands-on work) are cited at about the same rate as the things the program hopes educators will not particularly prioritize (tours and balance of work and play). Certainly, there are enough astronomy-related sites in Los Angeles that touring alone could fill a complete week, but NITARP trips are supposed to be research trips. The literature suggests students participating in short-term "flash and dash" science activities such as visiting a museum may positively change students' (or teachers') perceptions towards science; there is little research that demonstrates such events bring about long-term changes in perceptions of science or changing in understanding of the nature of scientific inquiry $[14,43]$.

Similarly, to enact changes in teachers' classrooms, PD opportunities need to offer targeted professional development over at least 50 hours [8]. Long-term professional development lasting 6-12 months has been linked to increased student achievement [9]. The NITARP program strives to provide such long-term interactions, and as such, despite the obvious appeal of sight-seeing, and despite the more mundane reality of sitting in a room in front of a computer, touring is not a priority; learning science by doing it should be the more influential take away from the 
trip, or at least the more influential in the long-term. However, the results seen in Fig. 3 suggest that teachers list the touring-related topics at a comparable rate as the research-related topics when asked about the best thing about the trip.

\section{Comfort with the unknown}

Through the authentic research experience, educators are taught a pattern of how to learn in a new way than they may have known before. The experience (and the $\mathrm{COP}$ ) provides materials to grow with. To this point, neither the organizers nor more generally the participants have recognized this as one of the products of the program; this theme emerged upon reading the surveys as part of this work.

Participants are thrust into an environment where the learning curve is steep. They are provided lots of active support as they learn, but nonetheless there is a lot to learn in a very short time. For many of these teachers, it has been a long time since they were students, and they have work to keep up. However, by the end of the year, they are much more comfortable with the unknown and learning new things. They have a personalized strategy (or set of strategies) to tackle significant new concepts or projects, or maybe just confidence that they will figure it out, given enough time. They are accustomed to a "comfortable frustration" level.

It is not easy to quantify this effect based on the available data. One way that can show evidence of this learning process is to see how people approach their second AAS. Their first AAS is overwhelming. But, for the second AAS, teachers know how to tackle it. Again, this is something that emerges from the answers they choose to provide; 40\% of the participants wrote responses similar to the following:

EVERYTHING had a different flavor this year. [...] I experienced everything through the lens of the research project of the past year. The entire experience was in context. Although I was interested in seeing what the other groups had done I was far more focused on the "what ifs" and "what next" of the process. I chose sessions based upon what I knew and how it would clarify some questions we had. I gravitated toward posters that related to our research and asked questions of people that continually filled gaps or opened up new questions.-NITARP educator, 2010 class

This experience convinced me even further that I can push myself to learn even more each and every day. I started out feeling very overwhelmed and unprepared last year. I forced myself to work through my unease and wound up much more comfortable.-NITARP educator, 2011 class

I now also have the tools to begin seeking out ways to expand this work on my own. I would not have had an easy start with this beforehand. [...] The skills this program provides are critical for student preparation and most teachers have not been given these. How can they then be expected to teach them?-NITARP educator, 2016 class

I feel like a popcorn kernel that has just burst open. I've grown so much at this meeting!-NITARP educator, 2013 class

By far the most interesting thing to me was the experience of presenting the poster. Not only did it make me feel like I was really part of the conference, it made me look back to the previous AAS when presenting a poster was not just very scary, it was almost inconceivable. So, what a journey! Reflecting on how overwhelmed and terrified I was last year, how hard I worked to learn everything, and then to be there actually doing it with some confidence, well...priceless.NITARP educator, 2012 class

I liked how I didn't know everything about my project to begin with. It made me become a better learner because I was asking the questions for understanding the content. In the end, I was in charge of my learning and I learned so much because of it.-NITARP educator, 2013 class

The most important thing I learned was that it's ok sometimes to not know the answer. As teachers, many times we become so consumed by having the right answer for students. Meanwhile, our students are so consumed by finding the right answer that they miss the learning. This week showed me that no matter how much work you do (in graph, periodogram, histogram, phase curve, or whatever form) you may still not come to the conclusion you thought you would... and that's ok!NITARP educator, 2013 class.

This experience will be hard to top. I may try to create a partnership with staff at a local university or community college to do more research projects. I also want to get better at programming. That is a valuable skill to share with students. NITARP helped me to see these opportunities.-NITARP educator, 2016 class

A second-order effect of this is that they now report being even more frustrated than they might have been before with traditional PD opportunities that are available.

I can say that my expectations for professional development in the future are such that I will not be satisfied with most opportunities that are offered locally. Thus, I feel that I will take the opportunity to offer PD to other teachers, particularly as it pertains to the nature of science or how to conduct research with archived data.-NITARP educator, 2016 class

No district-led professional development can compare [to NITARP]. I am very excited to lead some professional development opportunities in my district, but that is only a very small slice of the pie about NITARP. [...]I am looking actively to find other integrated professional development opportunities for teachers 
which make us step out of the classroom and work with professionals in the community.-NITARP educator, 2014 class

The BEST subject-area professional development experience I've had in 25 years BY FAR, and one of the most intellectually stimulating experiences I've had in years. I lie awake at night thinking about data.-NITARP educator, 2014 class

I have said this many times and will continue. I have been a teacher for 38 years, and have been in probably 18-20 special programs over that time to improve myself as a science teacher. The NITARP program ranks as one of the three best programs I have been in over that period of time.-NITARP educator, 2013 class

\section{Student empathy}

NITARP requires a lot of its educators and students. Even those who begin participation knowing that they will need to work hard are frequently overwhelmed. For many educators, it has been a long time since they have been in the position of a learner, especially one struggling to understand; they admit that they have forgotten what it is like to be a student. Some educators (about $7 \%$ of our sample) explicitly note, without being prompted to do so, that as a result of their experience, they now have much more empathy for their overwhelmed students. While the occasional instance of this in feedback forms had been noted, combing feedback forms as part of this work made this theme crystallize better than it had before.

It is notable that these statements of student empathy come most commonly, but not solely, from educators who are often the most overwhelmed educators, those who, at first appraisal, may seem to not have gotten much out of the experience. Increased student empathy is a clear benefit to those educators (and their students), even if they did not understand all the rest of the experience to the depth one might wish.

I got to experience what it's like to be a student struggling with exciting new material. This has increased my functional empathy with students. -NITARP educator, 2016 class

This experience will help me understand how students feel when they are presented with new material and don't understand. I think this will give me more patience and understanding in this area.-NITARP educator, 2012 class

\section{Pedagogical changes and professional growth}

\section{Professional growth}

As people develop professionally, they look for new experiences. Some people discover NITARP because they are specifically looking for new opportunities. At least $80 \%$ of participants report that they are actively seeking opportunities to learn, grow, and change as part of NITARP and that the program meets that need.

Some participants change career paths rather dramatically during or after their participation, often into positions that allow them greater influence over more educators and/ or policy. While, of course, the program cannot claim credit for all or even most of that, it may have facilitated it. Their experience may have opened the educators' eyes to different career paths than they might have previously known. This theme emerged from the first four years of NITARP (and the prior years with Spitzer), and was explicitly probed with survey questions for the second four years.

From alumni data, it is suspected that the program had a significant role in the career changes of at least 9 alumni ( $\sim 12 \%$ of all participants); however, records are incomplete. At least two of those, plus 2 more alumni, started graduate school in education at least in part as a result of their NITARP experiences. At least one more specifically mentioned her mentor educator experience as critical to her realization that she would prefer to teach teachers than be in her (then) current high school classroom. Several people moved up in their district's hierarchy such that they can teach teachers or set policy at a district (or higher) level; this is a positive outcome in that the influence of NITARP can then be extended to a larger community than would be possible had those teachers stayed in the classroom. Some now work for observatories or large astronomy projects as part of education efforts.

[...] I'm now a Science Instructional Coach who works mainly with teachers and I'm able to impart accurate information about what scientists really do to middle school science teachers who don't really know what that is. I'm able to help them design lessons and science fair projects that allow students to experience authentic research activities.-educator, 2005 class, writing in 2013

[...]my NITARP experience made my science department realize that we need to bring the use of real data into our curriculum. Since we are reorganizing because of the new science standards, it is an opportunity for us to do this. We realize the support for our students to handle large data sets will need to be scaffolded. Having worked with NITARP doing archival research I am now working with my dept. chair to bring a research component into all our science classes. The experience that I had with NITARP was so inspiring that I am more than willing to donate my time for this.-NITARP educator, 2012 class, writing in 2013

It is important to note that there is significant selection bias likely to be affecting these results. Educators who apply to participate are already looking for new opportunities to learn, grow, and change; in some sense, then, it is not surprising that a significant fraction change jobs. However, the magnitude of the changes, and the direction 
of the changes, in at least a few cases, are larger than would be expected for a highly capable classroom educator. The changes are attributed by the educators themselves to their NITARP experience, in part or in whole.

Because significant career change has emerged as a trend, participants are now probed more explicitly about professional goals, but this is still in the nascent stage. Additionally, there will need to be more complete and explicit surveying of alumni on longer time scales than the primary year to complete this kind of analysis; more time is needed to explore the ramifications of the program on longterm professional growth. Moreover, the effects on mentor educators (who spend several years on active teams) maybe be significantly different than participant educators (who spend only one year on a team).

More broadly, $14 \%$ of alumni used the words "life changing" when describing the impact of their research experience on their lives. NITARP provides PD at the level that high-achieving teachers need.

My NITARP experience has made me rethink my entire approach to science education. Many of my students expect me to do the work and pretty much hand it to them all wrapped up and neat. Science education must involve a great deal of discovery by the student and not a string of topics with definitions.—NITARP educator, 2012 class

My life has changed in some way because of my participation in this program. My wife, my children, and my co-workers have all remarked at how I am different now. I don't know whether it was the program, the people that I worked with, or some combination of the two, but whatever it was something about it changed me. I know that "life-changing experience" was not one of the outcomes that you hoped for when you planned the program, but it is what happened with me. Thank you very much for allowing me to participate-this has been one of the best years of my life.-NITARP educator, 2013 class

\section{Better science in their classrooms and their PD}

Information can be teased out about how more authentic science might be making its way into educators' classrooms and PD experiences that they lead. In one case, prior to their experience, one educator was proud of the "real research" he was helping students conduct at his school. After his experience, he reported that he realized that since he knew what answers the students would find before they started, that it clearly was not real research. One assumes that he then subsequently made changes to address this in his classroom, but that is an assumption.

The survey results, since they were collected during and immediately after the intensive NITARP experience, often reflect a realization on the educators' part that they need to change what they are doing in the classroom. Surveys over a longer time baseline covering what changes were actually made in the classroom (as opposed to changes they want to make) are beyond the scope of the present work. From examining survey results like this, though, at least $60 \%$ of the participating educators report that they want to bring more authentic ("better") science into their classrooms and into the PD they lead following participation in the program.

This theme emerged in the first 4 NITARP years and then was explicitly probed in the second 4 NITARP years.

[NITARP] has made me realize that while I use a lot of inquiry, I don't always involve my students in the process of developing a testable question. [...] The next time, I hope to involve my students more in the entire process. I plan on emphasizing that science is a collaborative effort.-NITARP educator, 2012 class

After this experience, I'm more aware that beyond just teaching my students good science, my focus should be to prepare them for a career in science. I feel like I have a better understanding of the skills they'll need to be successful. I've already made big changes to my curriculum because of this program, and will continue to do so in future years.-NITARP educator, 2012 class All of this is directly applicable to my classroom. What is it that makes some learners want, need, desire a cookbook style while others would rather discover for themselves? In a traditional classroom situation the learner who enjoys the freedom of less direction does not always fit the teacher's mold. This student might go off on interesting tangents as they investigate the topic at hand which isn't always easy to manage in a class of 30 students. Team work does not necessarily mean everyone is working hand in hand, but instead that the group is working towards the same end product, with each individual finding their own way at times. Individual work and subsequent sharing allows learners to leapfrog over each other towards the end product. So the question is, how do we balance direct instruction and open ended inquiry? How do we make the average learner more comfortable with the open ended approach? How do we pull away from "cookbook" learning and labs and free our learners to investigate the many possible paths to the end product? How much direct instruction is necessary and at what point to we leave the learner to their own devices to "figure things out?" I need to find more ways to make this happen in my own classroom. - NITARP educator, 2012 class My science department is already discussing how to bring in and scaffold both programming and use of existing data bases in all of our science classes as a result of my participation in NITARP and the demand of our students, based on feedback from our alumni.NITARP educator, 2012 class

I have a new view on doing research. I now understand the need for solid science programs at all levels as a 
foundation for future scientists, not just astronomers. This experience has made me reflect on my pedagogy and motivates me to continue to strive to improve my techniques.-NITARP educator, 2013 class

NITARP has made me realize that most science teachers don't really immerse students in real science. Too often we (myself included) do "labs" that have an answer and fit in a class period, and though NITARP has made me want to deviate from this, I'm still not exactly sure how yet. All I know is my students don't ask as many questions as they could be and should be and I need to work on it.-NITARP educator, 2013 class

I am more compelled than ever by the collaborative model of doing research with high school students. I also feel strongly that it is wonderful to expose students to the public archives. I will continue to work on exposing my introductory and advanced students to these two aspects of doing research.-NITARP educator, 2014 class

In our research course at school, I am pushing to change some of the parts of it that need updating and that don't really reflect the reality of scientific work. For instance, assembling a complete research proposal, which now seems so obvious, was not a requirement at school. I am also planning on providing students with opportunities to conduct research where they do not need to collect their own data. Why not? There's so much already out there.-NITARP educator, 2016 class

However, the ability to assess the degree of more or better science in the classroom is strongly affected by not only the questions asked of the educators, but how they were asked (and most likely what was discussed with the educators on any given team over the year). The literature based on other teacher research PD suggests that such changes are likely $[13,14,16,17]$. However, this topic specifically in the context of NITARP requires more work to fully understand, in particular both better questions and better post-NITARP follow-up to probe the longer-term impact on educators, and specifically how NITARP experiences influence classroom behavior on both the short and long term.

\section{E. Limitations}

The data used here are entirely self-reported data from a relatively small number of teacher participants, albeit highly capable teachers who can recognize changes in their approaches and/or philosophies. Moreover, the program is selective and the teachers highly motivated. Recurrent themes are triangulated between multiple surveys from the same person at different waypoints and multiple surveys at the same waypoint from different people. Increasing the sample size by simply waiting for more years to pass is possible, though NITARP itself, and the questions that are asked at the waypoints, change with time as the program continually readjusts to meet new needs. Longer time baseline studies of the same people over time are also desirable, to sample, for example, changes made in the classroom in response to NITARP.

Another limitation is that the data from the first four years used here often included incomplete or missing answers to questions (because of the survey design; see Rebull et al. [21]). As such, any information on some of the themes investigated here is not available (or not as clearly revealed) for those earlier participants.

Because some of the themes identified here emerged in the process of conducting this research, these themes were not explicitly probed with questions in the surveys. Interviews with participants specifically on the themes investigated here could also illuminate the themes investigated here. Investigating similar themes in student data is beyond the scope of this work.

This work does not track any changes in classroom instruction; it works primarily with teachers' perceptions and not how or when these perceptions impacted the classroom, beyond teachers explicitly stating that they were rethinking their approach. Classroom impact is left to future work.

\section{SUMMARY AND FUTURE WORK}

Despite the fact that many educators did not participate in authentic science research before being in the classroom, changes to science education in the U.S. continue $[2,4]$. As educators are asked to include more authentic science experiences in the classroom, there is increasing demand for PD that fills that gap. Since educators tend to teach in the same way in which they were taught $[3,44-46]$, if they have never conducted authentic science research, it can be very hard for them to teach students how to be engaged in scientific practice.

NITARP, the NASA/IPAC Teacher Archive Research Program, partners small groups of mostly high school classroom teachers with a research astronomer for a yearlong authentic astronomy research project. Operating since 2005, by 2017, the program has worked with a total of 103 educators from 34 states. The empirical data used in the qualitative analysis here focuses primarily on the last eight years (2010-2017) of surveys collected at up to 4 waypoints from 74 educator participants.

The original research question was the following: How do educator participants describe the major changes and outcomes in themselves fostered by NITARP? This is a summary of self-report evaluation data, though only about half of the themes discussed here were specifically targeted with survey questions.

Evidence was found that the program helps foster an array of skills in the participants. Following the program, educators have a more accurate view of the nature of science; $74 \%$ of teachers report some or major change in their understanding as a result of the program. Educators emerge with a better understanding of who astronomers are and qualities they possess; $60 \%$ list patience and/or 
persistence as important, $40 \%$ mention creativity, and $\sim 30 \%$ list collaboration and/or teamwork. The program fosters collaboration and sharing within their teams, and enables better subsequent sharing with other educators and scientists. The program provides an ongoing strong link to the astronomy research community. It helps educators to have more comfort with the unknown, and greatly increases their personal confidence in their ability to learn entirely new skills. At least $7 \%$ of participating educators report increased student empathy. The program fosters professional growth; at least $80 \%$ of educators say they participate because they are looking to learn, grow, and/or change. At least $12 \%$ have changed their career path significantly, based in part because of their NITARP experience. Moreover, 14\% of the alumni say the experience was life changing. And finally, the program enables more authentic science methods to be modeled, demonstrated and expected in the classroom; at least $60 \%$ of alumni self-report that the program changed what they want to do in the classroom.

The majority of research on science teachers' research experiences has focused on content knowledge gains, perceptions of science and scientists, changes in pedagogy, and teachers' interactions with scientists [12-17]. Teachers' frustrations with working through science research projects were noted in Burrows et al. [47]. There has been only limited systematic work on teacher research experiences $[18,19]$. This work adds to the existing body of literature to illuminate what teachers themselves say they have gained from the experience.

The results, analysis, and conclusions we make in this study are generalizable to other teacher research experience programs and, more importantly, open up more in-depth research questions for future exploration. Future research specifically can be envisioned into the impact of NITARP and similar PD programs. For example, it would be interesting to probe the effects on the student participants and on the students of participating educators in years subsequent to the intensive research experience year. The long-term impact of NITARP should be investigated, including specifically the impact on mentor educators, who spend multiple years in the program.

At the current funding level, only a few teachers per year can be involved in NITARP. Ideally, more teachers should be involved, over more science subjects. But until that goal is realized, NITARP alumni share their experience of what actually doing scientific research is really like with other educators who have no such experience. Sharing of their experience is required, specifically because so few educators can participate per year. The teachers who are reached only through the NITARP alumni could obviously learn more if they participated in NITARP, but, given the lack of resources, at least learning, peer to peer, about the nature of science, is a step in the right direction. For these second-order teachers who then want to begin by incorporating more data into their classrooms, they learn that archival data are available and that there are programs that incorporate real data into the classroom, even if not to the same rigor expected of NITARP participants (see, e.g., Rebull [48]).

The NGSS calls for teachers to implement more authentic practices in their science classrooms. Because many teachers lack the requisite training, PD programs such as NITARP are going to play an important role at helping teachers gain the knowledge and skill to implement the NGSS with fidelity. NITARP shows that these kinds of experiences are instrumental at changing teachers' attitudes and behaviors in the classroom. These results show that teachers are capable of doing science research and implementing authentic science in their classrooms. This work suggests that more PD programs should involve authentic research activities as part of their program. Such PD will first meet the higher-level needs of high achieving teachers; later, programs such as this could be expanded to provide the infrastructure enabling all teachers to be ready to engage in authentic research, and then support them in that endeavor. If PD providers have high expectations for their teachers, then those expectations can be met, just as high expectations for students can be met [49].

\section{ACKNOWLEDGMENTS}

Thank you to all 103 NITARP and Spitzer educators for your tireless devotion to this program. Support for this program was provided in part by NASA/ADAP (Astrophysics Data Analysis Program) funds. Thank you Doug Hudgins. Thanks to Martha Kirouac and Tim Spuck for useful suggestions on early drafts.
[1] G. E. DeBoer, The history of science curriculum reform in the United States, Handbook of Research on Science Education, edited by N. G. Lederman and S. K. Abell (Routledge, New York, 2014), Vol. II, pp. 559-578, https:// www.researchgate.net/publication/282647128_The_History _of_Science_Curriculum_Reform_in_the_United_States.
[2] NGSS Lead States, Next generation science standards: For states, by states, 2013, https://www.nap.edu/catalog/18290/ next-generation-science-standards-for-states-by-states.

[3] B. Crawford, From inquiry to scientific practices in the science classroom, Handbook of Research on Science Education, edited by N. G. Lederman and S. K. Abell 
(Routledge, New York, 2014), Vol. II, pp. 515-544, DOI: $10.4324 / 9780203097267 . c h 26$.

[4] National Research Council of the National Academies, A Framework for K-12 Science Education: Practices, Crosscutting Concepts, and Core Ideas (National Academies Press, Washington, DC, 2012), https://www .nap.edu/catalog/13165/a-framework-for-k-12-science-edu cation-practices-crosscutting-concepts.

[5] M. Marder, Recruiting teachers in high needs stem fields, Bull. Am. Phys. Soc. 62 (2017), https://www.aps.org/ policy/reports/popa-reports/upload/POPASTEMReport.pdf.

[6] National Science Board, National science board science and engineering indicators 2012, 2012, https://www.nsf .gov/statistics/seind12/start.htm.

[7] O. K. Stalnaker, S. Evans, T. Rutherford, J. Taylor, and L. Rebull, NITARP: Bridging the Gap Between the Traditional Science Classroom and Authentic Research, Am. Astron. Soc. Abs. 231, 155.04 (2018), https://ui .adsabs.harvard.edu/\#abs/2018AAS...23115504S/abstract.

[8] R. C. Wei, L. Darling-Hammond, A. Andree, N. Richardson, and S. Orphanos, National staff development council (ERIC, 2009), https://learningforward.org/docs/default-source/pdf/ nsdcstudytechnicalreport2009.pdf.

[9] K. S. Yoon, T. Duncan, S. W.-Y. Lee, B. Scarloss, and K. L. Shapley, Reviewing the evidence on how teacher professional development affects student achievement. issues \& answers. rel 2007-no. 033. Regional Educational Laboratory Southwest (NJ1) (2007), https://eric.ed.gov/? id=ED498548.

[10] M. T. Fitzgerald, R. Hollow, L. M. Rebull, L. Danaia, and D. H. McKinnon, A review of high school level astronomy student research projects over the last two decades, Pub. Astron. Soc. Aust. 31, e037 (2014).

[11] J. A. Taylor and T. M. Dana, Secondary school physics teachers' conceptions of scientific evidence: An exploratory case study, J. Res. Sci. Teach. 40, 721 (2003).

[12] M. Dresner and E. Worley, Teacher research experiences, partnerships with scientists, and teacher networks sustaining factors from professional development, J. Sci. Teach. Educ. 17, 1 (2006).

[13] A. K Houseal, F. Abd-El-Khalick, and L. Destefano, Impact of a student-teacher-scientist partnership on students' and teachers' content knowledge, attitudes toward science, and pedagogical practices, J. Res. Sci. Teach. 51, 84 (2014).

[14] S. Laursen, C. Liston, H. Thiry, and J. Graf, What good is a scientist in the classroom? participant outcomes and program design features for a short-duration science outreach intervention in $\mathrm{K}-12$ classrooms, CBE-Life Sci. Educ. 6, 49 (2007).

[15] J. Raphael, S. Tobias, and R. Greenberg, Research experience as a component of science and mathematics teacher preparation, J. Sci. Teach. Educ. 10, 147 (1999).

[16] J. F. Westerlund, D. M. Garca, J. R. Koke, T. A. Taylor, and D. S. Mason, Summer scientific research for teachers: The experience and its effect, J. Sci. Teach. Educ. 13, 63 (2002).

[17] M. R. Blanchard, S. A. Southerland, and E. M. Granger, No silver bullet for inquiry: Making sense of teacher change following an inquiry-based research experience for teachers, Sci. Educ. 93, 322 (2009).

[18] S. R. Buxner, Exploring how research experiences for teachers changes their understandings of the nature of science and scientific inquiry, J. Astron. Earth Sci. Educ. 1, 53 (2014), https://eric.ed.gov/?id=EJ1101086.

[19] T. Sadler, S. Burgin, L. McKinney, and L. Ponjuan, Learning science through research apprenticeships: A critical review of the literature, J. Res. Sci. Teach. 47, 235 (2010).

[20] http://nitarp.ipac.caltech.edu.

[21] L. M. Rebull, M. Fitzgerald, T. Roberts, D. A. French, W. Laurence, V. Gorjian, and G. K. Squires, Motivations of educators for participating in NITARP, an authentic astronomy research experience professional development program, Phys Rev. Phys. Educ. Res. 14, 010148 (2018).

[22] L. M. Rebull, M. Fitzgerald, T. Roberts, D. A. French, W. Laurence, V. Gorjian, and G. K. Squires, The NASA/IPAC teacher archive research program (NITARP), Proceedings of the Robotic Telescopes, Student Research, and Education Conference, 2017 (2018) [arXiv:1804.08743].

[23] R. K. Yin, Case Study Research: Design and Methods (5th ed.) (SAGE Publications, Thousand Oaks, CA, 2014), https://www.amazon.com/Case-Study-Research-MethodsApplied/dp/1452242569.

[24] M. Koro-Ljungberg, D. Yendol-Hoppey, J. J. Smith, and S. B. Hayes, (e) pistemological awareness, instantiation of methods, and uninformed methodological ambiguity in qualitative research projects, Educ. Res. 38, 687 (2009).

[25] J. W. Creswell and C. N. Poth, Qualitative Inquiry and Research Design: Choosing among Five Approaches (Sage Publications, Thousand Oaks, CA, 2017), https:// www.amazon.com/Qualitative-Inquiry-Research-Interna tional-Student/dp/150636117X/ref=dp_ob_title_bk.

[26] J. W. Creswell, Research Design (Sage Publications, Thousand Oaks, CA, 2014), https://www.amazon.com/ Qualitative-Inquiry-Research-Design-Approaches/dp/14129 95302.

[27] NSTA, Nsta position statement: Professional development in science education 2006. Accessed (2017), http://www .nsta.org/about/positions/profdev.aspx.

[28] J. Lave and E. Wenger, Situated Learning: Legitimate Peripheral Participation (Cambridge University Press, Cambridge, England, 1991), https://www.amazon.com/ Situated-Learning-Participation-Computational-Perspecti ves/dp/0521423740.

[29] E. Wenger, R. A. McDermott, and W. Snyder, Cultivating Communities of Practice: A Guide to Managing Knowledge (Harvard Business Press, Cambridge, MA, 2002), https://hbr .org/product/cultivating-communities-of-practice-a-guideto-managing-knowledge/3308-HBK-ENG.

[30] E. Wenger-Trayner and B. Wenger-Trayner, Introduction to Communities of Practice: A Brief Overview of the Concept and its Uses (2015), http://wenger-trayner.com/ introduction-to-communities-of-practice/.

[31] D. C. Wells, E. W. Greisen, and R. H. Harten, FITS-a Flexible Image Transport System, Astron. Astrophys. Suppl. Ser. 44, 363 (1981), https://ui.adsabs.harvard.edu/ \#abs/1981A\&AS...44..363W/abstract. 
[32] L. M. Rebull, V. Gorjian, C. Brinkworth, G. K. Squires, and K. Burtnyk, NITARP: Impact Assessment, 2005-2013, Am. Astron. Soc. Abs. 223, 249.01 (2014), https://ui .adsabs.harvard.edu/\#abs/2014AAS...22324901R/abstract.

[33] N. G. Lederman, Students' and teachers' conceptions of the nature of science: A review of the research, J. Res. Sci. Teach. 29, 331 (1992).

[34] N. G. Lederman, Nature of science: Past, present, and future, Handbook of Research on Science Education, edited by N. G. Lederman and S. K. Abell (Routledge, New York, 2007), Vol. II, pp. 831-879, https://books .google.com/books?hl=en\&lr=\&id=Rd31m3_RU3oC.

[35] D. W. Chambers, Stereotypic images of the scientist: The draw- a-scientist test, Sci. Educ. 67, 255 (1983).

[36] D. Yang and M. Zhou, Exploring lower-secondary school students' images and opinions of the biologist, J. Baltic Sci. Educ. 16, 855 (2017), http://oaji.net/articles/2017/9871513970788.pdf.

[37] K. J. Schneider, Impact of teacher scientist partnerships on high school students'perceptions of science, Vol. 430 (2017), https://scholarworks.uni.edu/etd/430.

[38] J. A. Frogel, Astronomy's greatest hits: The 100 most cited papers in each year of the first decade of the 21st century (2000-2009), Publ. Astron. Soc. Pac. 122, 1214 (2010).

[39] H. A. Abt, Citations and team sizes, Publ. Astron. Soc. Pac. 129, 024008 (2017).

[40] R. B. Freeman and W. Huang, Strength in diversity: Richard B. Freeman and Wei Huang reflect on a link between a team's ethnic mix and highly cited papers, Nature (London) 513, 305 (2014).

[41] D. Slavit, T. H. Nelson, and A. Kennedy, Perspectives on Supported Collaborative Teacher Inquiry (Routledge, New York, 2009), https://www.amazon.com/PerspectivesSupported-Collaborative-Routledge-Education/dp/0415999 $26 X$.
[42] T. H. Nelson, Knowledge interactions in teacher-scientist partnerships: Negotiation, consultation, and rejection, J. Sci. Educ. 56, 382 (2005).

[43] E. Şentürk and Ö. F. Özdemir, The effect of science centres on students' attitudes towards science, Int. J. Sci. Educ. 4, 1 (2014).

[44] P. L. Brown, S. K. Abell, A. Demir, and F. J. Schmidt, College science teachers' views of classroom inquiry, Sci. Educ. 90, 784 (2006).

[45] R. A. Duschl, H. A. Schweingruber, and A. W. Shouse, Learning progressions, Taking science to school: Learning and teaching science in grades K-8 213 (2007), https:// www.nap.edu/catalog/11625/taking-science-to-school-learn ing-and-teaching-science-in-grades.

[46] H. Quinn, H. Schweingruber, and T. Keller, National research council, committee on a conceptual framework for new $\mathrm{K}-12$ science education standards, A framework for $\mathrm{K}-12$ science education: practices, crosscutting concepts, and core ideas (2012), https://www.nap.edu/catalog/ 13165/a-framework-for-k-12-science-education-practicescrosscutting-concepts.

[47] A. C. Burrows, M. A. DiPompeo, A. D. Myers, R. C. Hickox, M. Borowczak, D. A. French, and A. C. Schwortz, Authentic science experiences: Pre-collegiate science educators-successes and challenges during professional development, Science 70, 60 (2016), http://www .scientiasocialis.1t/pec/node/1010.

[48] L. M. Rebull, Authentic research in the classroom for teachers and students, Proceedings of the Robotic Telescopes, Student Research, and Education Conference, 2017 [arXiv:1804.08747].

[49] R. J. Marzano, The Art and Science of Teaching: A Comprehensive Framework for Effective Instruction (ASCD, Alexandria, VA, 2007). 